\title{
Aproximaciones a la política exterior Latinoamericana
}

Con ocasión del décimo aniversario de la revista "Estudios Internacionales", Claudio Véliz ${ }^{1}$ hizo un intento por evaluar la nueva política exterior latinoamericana y llegó a una desilusionadora conclusión: tan sólo dos países, a saber, el Brasil y Cuba, lograron tener una actuación autónoma en el sistema internacional. $Y$, dicho sea de paso, en ambos casos a través de iniciativas emprendidas en el Africa. Este severo juicio emitido por Véliz es el resultado de una definición estricta de la política exterior, que exige de quienes tienen el poder de tomar las decisiones algo más que una simple participación en el Diálogo Norte-Sur, más que el mero equilibrio entre el Primer y el Tercer Mundo, más que las escaramuzas en las filas de los "77" o en el seno de la UnCTAD. Es obvio que a ese nivel todos los países de América Latina y del Caribe, sin considerar la cooperación o la confrontación intracontinental, sí participen en el sistema internacional.

La mera secuencia de los hechos de la política internacional no constituye todavía una política exterior sistemática. (Es por esta razón que resulta poco satisfactorio la lectura del resumen redactado por varios analistas estadouniden ses sobre la política exterior latinoamericana) ${ }^{2}$.

Por otra parte, el hecho de que existan dos estados autónomos en materia de política exterior, debe interpretarse como un paso hacia adelante en relación con situaciones pasadas, en las cuales los latinoamericanos habían sido calificados de pasivos por observadores reconocidos como, por ejemplo, Norman Bailey ${ }^{3}$. En su texto- uno de los análisis más autorizados de la década de los sesenta, el continente aparece en el escalón más bajo -el de los estados clientelistas - clasificado en cuatro categorías posibles de comportamiento en materia de política exterior. $\mathrm{Ni}$ siquiera un analista latinoamericano de' la actualidad, el mexicano González Aguayo ${ }^{4}$, quien intentó presentar un modelo jerárquico derivado

\footnotetext{
${ }^{1}$ Claudio Véliz, "Errores y omisiones: notas sobre la política exterior de los países de América Latina durante los últimos diez años". En: Estudios Internacionales (Buenos Aires), x (1977) $4^{\circ}$.

${ }^{2}$ Harold Augene Davis and Larman C. Wilson (eds.), Latin American Foreign Policies. An Analysis.

Baltimore: The Johns Hopkins University Press, 1975.

${ }^{3}$ Norman A. Bailey, "Latin America in World Politics" New York, 1967.

${ }^{4}$ Leopoldo González Aguayo, "Notas sobre el sistema de relaciones internacionales de América Latina”. En: Relaciones Internacionales (México), v (1977) 19.
} 
de estratificaciones sociales, ve por ahora ninguna posibilidad de que uno de los estados del Hemisferio Sur pueda aspirar a pertenecer a la "clase alta".

En el siglo XIX y a principios del XX, época en que los estados del Cono Sur se contaban entre los países desarrollados del mundo y producían cancilleres activos, América Latina se perfilaba al menos periódicamente. Sin embargo, pasada la Segunda Guerra Mundial, a duras penas se logró un comportamiento clientelista subordinado. ¿Puede acaso deducirse de esto que en 1945 habría tenido lugar una reestructuración del sistema internacional que limitara la libertad de acción de Latinoamérica? O, por el contrario, ¿hubo estados latinoamericanos que lograron liberarse y salir a flote en los últimos 15 años? A la luz de estas dos preguntas, que ambas debieran contestarse afirmativamente, se desarrollarán a continuación las siguientes observaciones:

En la discusión en torno al "Nuevo Orden Económico Internacional" resulta útil remitirse a los años comprendidos entre 1944 y 1948, durante los cuales, efectivamente, surgió un nuevo orden, y que es precisamente aquel que se trata de corregir hoy. Sobre los escombros que dejara la Segunda Guerra Mundial se establecieron dos superpotencias: los Estados Unidos y la Unión Soviética, cuya acumulación de poder rompió las barreras del clásico estado-nación creando un sistema hegemónico global que les asignaba un papel de tercera importancia a los demás actores de la escena internacional.

Según el modelo original, el mundo debía ser administrado conjuntámente por las dos superpotencias a través de las Naciones Unidas, entonces recientemente creadas. Pero el antagonismo ideológico que iba surgiendo entre Moscú y Washington fue la causa de que se formaran dos bloques paralelos de pactos y alianzas de carácter imperial. Latinoamérica rica participó en esta "creación_- 5 mediante aportes al debate pero, por supuesto, no pudo influir en las decisiones importantes. Si bien es cierto que a través de la Conferencia de Chapultepec, celebrada en 1945, el continente intentó salvar las prioridades regionales frente al universalismo de Dumbarton Oaks, conferencia en que se hicieron los preparativos para la fundación de las Naciones Unidas y de la cual Latinoamérica quedará excluida. Los Estados Unidos lograron enseguida imponer una perspectiva global en todos los puntos, ceñida a sus propios intereses e ins-

En uno de los primeros trabajos de Galtung, América Latina se describe como un sistema feudal subordinado a Ios Estados Unidos. Véase Johan, Galtung et. al: El Sistema Latinoamericano de Naciones: un' análisis estructural. En América Latina (Rio de Janeiro), IX (1966) 1.

${ }^{5}$ Dean Acheson, "Present at the Greation. My years in the State Department". New York: 1969. 
titucionalizarla ${ }^{6}$ en los pactos del TIAAR (Tratado Interamericano de Asistencia Recíproca) y la OEA (Organización de los Estados Americanos), cuya fundación venía aplazándose deliberadamente hasta los años 1947/48. En un principio, América Latina cifró sus esperanzas en su propio desarrollo y buscó aliados internacionales para llevarlo a cabo. Sin embargo, la "Carta de La Habana" no propició el desarrollo de un sistema equilibrado de comercio internacional y al no implementarse el organismo que en ella se preveía ("International Trade Organization" $\mathrm{ITO}^{7}$ ) sólo tuvo por resultado algunos fragmentos como el GATT, con los cuales los Estados Unidos pudieron apretar aún más las mallas de aquella red institucional que había arrojado sobre América Latina junto con el nuevo ordenamiento de su mundo.

Debido a la homogenización ideológica de los pactos, que fue posible gracias al anticomunismo de la guerra fría, tan candente en esa época, Latinoamérica no encontró alternativa alguna para proceder autónomamente. Un intento que hiciera la Argentina peronista por tomar otro camino, no pudo sostenerse en el aislamiento. En vista de las presiones ejercidas desde Washington, en donde se denunciaba falseando la historia deliberadamente, a ese estado sudamericano de "carácter típicamente nazi-fascista" y donde se le amenazaba con impedirle el ingreso a las Naciones Unidas", esta "tercera posición" de Perón se desmoronó, volviéndose un callejón sin salida, que sólo pudo abrirse mediante una adaptación de su política exterior.

Otros estados latinoamericanos, incapaces de captar el repentino cambio cualitativo ocurrido en el orden mundial de 1945 y todavía aferra-

\footnotetext{
${ }^{6}$ Véase Lothar Brock, Entwicklungsnationalismus und Kompradorenpolitik. Die Gründung der oAs und die Entwicklung der Abahängigkeit Lateinamerikas von den USA. Meisenheim: Anton Hain, 1975.

Véase también Gordon Connel-Smith, The United States \& Latin America. A Historical Analysis of Inter-American Relations. London: 1974.

${ }^{7}$ Manuel Casanova. "El sistema económico internacional de la postguerra: la participación de América Latina". En: Estudios Internacionales, (Santiago de Chile, xII,
(1979), 46.

También William Diebold, Jr., The end of rTo. Princeton Essays in International Finance. Nr. 16, October 1952.

${ }^{8}$ Ernest R. May. Un caso ilustrativo del enfoque de la "política burocrática": Las Relaciones entre Estados Unidos y la Argentina en el período 1942-1947. En: J. Cotler-R. Fagen (eds.) Relaciones Políticas entre América Latina y Estados Unidos. Buenos Aires: 1974. Además: Pedro E. Egea Lahore, Argentina en la conferencia de San Francisco. En: Revista Argentina de Relaciones Internacionales. (Buenos Aires) II, (1976) 4. Antes de 1945, los Estados Unidos aún se encontraban con barreras a la hegemonía. Véase Michael J. Francis, The Limits of Hegemony: US Relations with Argentina and Chile during World War II. Notre Dame: University of Notre Dame Press, 1977. Un caso paralelo a la Argentina rebelde, a saber, la Venezuela democrático-nacionalista de 1945-48 se hundió en la dictadura
de Pérez Jiménez con sus lealtades frente a Washington.
} 
d's al concepto clásico de la soberanía, empezaron a maquinar revueltas lo: sales contra el poderío central de los Estados Unidos, pero en cada uro de los casos fracasaron deplorable o trágicamente. Estaban llamados a fallar porque los determinismos del sistema imperial estadounidense, de ideología muy severa, resultaban tan rígidos en la competencia con la Unión Soviética que no quedaba otra alternativa. Es en este sistema de seguridad, orientado en forma bipolar, en el cual América Latina perdió su relación especial con Washington (aunque de palabra seguía aferrada a ella) y se rebajó a constituir uno de los eslabones de una cadena de pactos, era obvio que, todo intento por lograr una autonomía en la política exterior apareciese como un triunfo potencial de la contraparte, y, por ende, como una sublevación. En el acto sobrevenía el castigo, ya sea en forma directa o indirecta. Cole Blasier ${ }^{9}$ calificó las reacciones provocadas por tales insubordinaciones latinoamericanas contra el imperio como una forma de mecanismo automático de parte de Washington.

Si América Latina se hubiese percatado de ello mediante un análisis propio, se habría podido tomar medidas preventivas contra algunos desarrollos trágicos, semejantes, entre otros, al sucedido en 1973 en el Chile de Allende, que practicaba provocantemente un estilo revolucionario, para luego asombrarse por el veto impuesto por Washington. Para fines didácticos, el mecanismo automático de reacciones norteamericanas se puede ilustrar más claramente aún, comparando los comportamientos de los dos subsistemas dependientes, Latinoamérica y Europa Oriental, en su relación con la potencia central respectiva ${ }^{10}$. Si se transpone el caso de Guatemala 1954 o de Santo Domingo 1965, tenemos los de Hungría 1955 - Checoslovaquia 1968; Cuba fue una Albania, la doctrina Monroe corresponde a la doctrina de Brezhnev, etc. ${ }^{11}$. El meollo de la comparación radica en comprender la idea de que las élites de un sistema imperial, ya sea "socialista" o "capitalista", intervienen cuando quiera que crean estar perdiendo una ficha en el dominó de su propio sistema. Por esta razón, a partir de 1945, ambos sistemas hegemónicos vienen aplicando sanciones contra los disidentes, reales o supuestos, entre los cuales, los

${ }^{9}$ Cole Blasier, "The Hovering Giant. US Responses to Revolutionary Change in Latin America". University of Pittsburgh Press, 1976. 1976.

${ }^{10}$ Edy Kaufman, "The Superpowers and their Sphere of Influence. New York,

Además, Iris M. Laredo, Problemática de la solución de conflictos intrabloques: casos Guatemala, Hungría, Cuba, Santo Domingo, Ghecoslovaquia. Buenos Aires: Editorial Depalma, 1970.

${ }^{11}$ Robert K. Furtak, Las funciones y las consecuencias de las doctrinas Monroe y Brezhnev: una contribución a la discusión sobre la dependencia. En: Foro Intemacional (México), Xvi (1976) 3. 
casos de Guatemala 1954, República Dominicana 1965 y Chile 1973 fueron los que en América Latina tuvieron el desenlace más trágico.

Cabe anotar a estas alturas los intentos de interpretación hechos a raíz de las catástrofes. Después de la guatemalteca de 1954, Juan José Arévalo $^{12}$ escribió su fábula, hoy olvidada, del tiburón y las sardinas, redactada sin mayor capacidad analítica, simplemente como una perorata apasionada y resentida contra los Estados Unidos: un texto clave sobre la impotencia latinoamericana ante la rigidez del sistema americano.

Después de 1965, Juan Bosch ${ }^{13}$ plantea su tesis del pentagonismo, que nada tiene que envidiarle a su enojo a la fábula de Arévalo, pero que debido a sus incursiones en la ciencia política resultó más acertada. Para resumir la experiencia chilena de 1970 a 1973, J.A. Silva Michelena ${ }^{14}$ elaboró para la editorial mexicana Siglo XxI un ambicioso texto que comienza en forma optimista incluso en tiempo de Allende, aplicando la teoría de la dependencia sobre la política exterior latinoamericana, pero que concluye en 1977 con un sentimiento de resignación: ni en la década de los setenta ni en la de los ochenta se lograrían imponer cambios trascendentales en el sistema americano.

Es sólo a fines de los años setenta que un latinoamericano, Helio Jaguaribe $^{15}$, emprende un extenso análisis de la política exterior, de los determinismos que encadenan al continente como conjunto clientelista, al bloque hegemónico norteamericano, y advierte la posibilidad de avanzar para pasar de esa impotente marginalidad a una "autonomía periférica”.

Un realismo de esta índole, que desenmascara las ilusiones del estado nacional soberano, a la larga seria probablemente más ventajosa que los castillos en el aire que construyen los geopolíticos latinoamericanos ${ }^{16}$.

${ }^{12}$ Juan José Arévalo, Fábula del tiburón y las sardinas. Redactada en el exilio chileno en 1955-56, numerosas ediciones. La falta de experiencia diplomática de Guatemala se comenta tambiẻn en otras partes: "The main lesson learnt by the governments of Latin America from the Guatemalan crisis was that in the face of a major international crisis they were inexperienced and without articulate policies". F. Parkinson, Latin America, the Gold War \& the World Powers 1945-1973. A Study in Diplomatic History. London: Sage Publications, 1974, p. 46.

${ }^{13}$ Juan Bosch, El Pentagonismo, sustituto del imperialismo. Escrito originalmente como documento para una reunión de politólogos, luego editado por la Editorial Mexicana Siglo xxi.

La sucesión de hechos dominicanos está resumida en Piero Gleijeses, The Dominican Crisis. Baltimore: Johns Hopkins University Press, 1978.

${ }^{14}$ José A. Silva Michelena, Política y bloques de poder. Crisis en el sistema mundial. México. Siglo xxı, 1976.

${ }^{15}$ Helio Jaguaribe, Autonomía periférica y hegemonía céntrica. En: Estudios Internacionales (Santiago de Chile), xir (1979), 46.

${ }^{16} \mathrm{La}$ geopolítica, desaparecida en Europa después de 1945, sigue proliferando sobre todo en la parte austral de América del sur, donde apasionados geopolíticos clavan 
Este comportamiento, que por una parte se obstina en mantener la ficción de la autonomía en materia de política internacional, pero que, por otra, contribuye a atizar los conflictos fronterizos entre los países latinoamericanos, sacando así aún más el ya mermado poder negociador del continente.

Dejando a un lado el ejemplo atípico de Cuba (como "accidente" del sistema interamericano) se llega a la conclusión de que, los políticos, como los analíticos latinoamericanos, se demoraron treinta años en comprender los determinismos del sistema imperial estadounidense. Sin embargo, aunque Washington por lo pronto sólo tolere la "autonomía periférica", no hay motivo, ni necesidad, de tirar la toalla. Con la perspectiva que ofrecen tres décadas de experiencias con la Unión Soviética, nos podemos dar cuenta de los campos de acción de algunos de los estados clientelistas de la Europa Oriental: tanto Rumania como Hungría pudieron conquistar un máximo de autonomía local, a pasos pequeños y bien meditados, y aprovechando las constelaciones históricas. ¿Existe acaso un caso comparable en América Latina? Indudablemente que sí, y lo comprobaremos a continuación:

Para el efecto nos parece conveniente hablar de un proceso de aprendizaje de política exterior escalonado por generaciones, por el cual han pasado los estados latinoamericanos $y$, durante el cual la lógica del sistema americano, diagnosticando y elaborando, dando saltos de calidad, va siendo habilitada para la práctica política ${ }^{17}$.

El primer logro, ya histórico, corresponde a una generación de economistas latinoamericanos, que dirigidos por el argentino Raúl Prebisch, formularon un importante diagnóstico en la sede de la Comisión Económica para la América Latina (CEPAL), en Santiago de Chile.

En 1980, es verdad, el cepalismo más bien parece un lugar común en la política del desarrollo. 'Por esta razón cabe remitirse a la situación reinante durante la postguerra, cuando contrariamente a la ortodoxia librecambista establecida por los economistas internacionales, algunos latinoamericanos vislumbraron la posición asimétrica que estaba asumiendo el continente en el mundo y elaboraron, para corregir dicha defor-

sus flechas de conflicto en el mapa latinoamericano. Como inventario de la geopolítica latinoamericana, véase John Child, Geopolitical Thinking in Latin America. En: Latin American Research Review (Chapel Hill), xIv (1979) 2.

${ }^{17}$ Con ello nos apartamos de la acostumbrada división de la historia latinoameriçana de la postguerra en períodos en la cual se suelen destacar ante todo: los gobiernos presidiales populistas de finales de la década de los cincuenta (por ejemplo, en Argentina y Brasil). A título de ejemplo, véase la obra colectiva de autores de la RDA, Lateinamerika im antiimperialistischen Kampf. Probleme eines Kontinents. Berlin: Akademieverlag 1978. 1978. 
mación, una serie de conceptos político-económicos en torno al comercio exterior, la integración, la planeación, la intervención del Estado, la "dimensión social" del desarrollo, etc. ${ }^{18}$.

América Latina tuvo que contraponer la CEPAL a la resistencia ofrecida por los Estados Unidos, una vez que vio claramente que las aspiraciones formuladas originalmente en Chapultepec no podrían convertirse en realidad dentro de la onU o de la Organización de Estados Americanos, dominada por Washington. En el cuartel de la CEPAL - abierto en forma provisional en Santiago en el año 1948, pero establecido definitivamente en 1951 - a una distancia segura de Washington, Raúl Prebisch desarrolló, con ayuda de los economistas más audaces del continente, aquella labor intelectual que haría época y que gracias a la cual fue posible crear la política latinoamericana del desarrollo. Es precisamente porque los más destacados científicos internacionales se mofaban de su diagnóstico o le acusaban de hereje, que queremos establecer una comparación entre el argentino y el autodidacta alemán Friedrich List, quien, antes de 1846, calificó de infranqueable la brecha que existía entre la "subdesarrollada" Alemania y la Gran Bretaña, a menos de que se tomara todo ese paquete de medidas proteccionistas e intervencionistas que formaban el núcleo de su "teoría de escalas"19, para así ir reduciendo esas lagunas.

El genio del joven Prebisch fue más allá del diagnóstico en sí, puesto que comprendió la posibilidad que América Latina tenía que aliarse, cuando el orden mundial bipolar se abrió en abanico debido a los estados nuevos del Africa y de Asia que aún no estaban claramente comprometidos. Al sentido de táctica de Prebisch, Latinoamérica debe la apertura, a principios de la década de los sesenta, hacia foros de escala mundial, siendo ejemplo notorio el de la primera Conferencia de la UNCTAD, celebrada en 1964, que globalizara en cierta forma el Cepalismo. Cabe recalcar esta apertura de América Latina pues, gracias a la cual se inicia una fase de aprendizaje cuyos resultados constituyen durante mucho tiempo la base de las iniciativas tomadas en el campo de la política exterior. La actividad preparatoria de Prebisch en relación con la unCTAD señaló el rumbo de la marcha, y gracias a ella, los debates locales latinoamericanos cobraron calibre internacional.

\footnotetext{
${ }^{18}$ Fernando H. Cardoso, La originalidad de la copia: la cepal y la idea de desarro1lo. En: Revista de la CEPAL, Segundo Semestre de 1977.

David H. Pollock, La actitud de los Estados Unidos hacia la CePal. En: Revista de la CEPAL, Segundo Semestre de 1978.

${ }^{19}$ Acerca de List como "político del desarrollo", véase K.W. Kapp, Friedrich List's Contribution to the Theory of Economic Development. En: The Political Science Re. view (India), I (1962) 1.
} 
En un orden mundial, inflado por los nuevos estados africanos y asiáticos y mermado en su bipolaridad, los representantes del hemisferio austral empezaron a buscar adeptos, sondeando, con cierto recelo en un principio, el Tercer Mundo, tanto geográfica como conceptualmente. A raíz de la pregunta: ¿pertenece América Latina al Tercer Mundo ${ }^{20}$, se desencadenó una apasionada controversia, cuyo movimiento de vaivén entre "tercermundistas" y "occidentalistas" persiste todavía a principios de los años ochenta. Sin embargo: los críticos más acervos del tercermundismo aguzaron la vista para apreciar escalas más amplias, mejores posibilidades de coalición y de negociación.

-Fue justamente México, un país muy reservado en materia de política exterior, el que entonces comprendió la necesidad de evaluar en forma analítica las nuevas experiencias. Mientras el Presidente Alfonso López Mateos (1958-64) sentaba como precedente los primeros viajes al exterior, en 1959, en el Colegio de México se inauguraba el Departamento de Estudios Internacionales y aparecía, a mediados de 1960, el primer número de la revista "Foro Internacional" bajo la dirección del visionario Daniel Cosio Villegas.

Obrando en representación de América Latina, México comenzó así a sustituir a los autores norteamericanos importados y traducidos al español sin adaptación alguna (entre ellos, Hans J. Morgenthau, la figura más destacada de los "realistas"), por análisis propio, más acordes con las necesidades del continente latino americano" ${ }^{21}$.

En cambio, el Brasil se lanzó de una vez a la práctica, convirtiéndose en el primer estado latinoamericano activo en el movimiento de los No-alineados, haciéndolo precisamente en un momento en que los Estados Unidos reaccionaban ante el "accidente de Cuba", modernizando el sis =. tema de pactos de 1945-48, por medio del instrumento de la Alianża para el Progreso (con la cual se consagró el buen uso del vocabulario reformista, que, en 1954 se tildaba de escandaloso en Guatemala). Por supuesto, el Brasil no tuvo oportunidad de ir muy lejos en su acercamiento al Tercer Mundo, ya que el primero de abril de 1964, la "revolución conservadora" de los militares modificó la política exterior que había sido abierta en abanico por el Itamaraty, simpatizando cada vez más con múltiples opciones.

Las primeras experiencias colectivas con impacto son aquellas reali-

${ }^{20}$ Gino Germani, ¿Pertenece América Latina al Tercer Mundo? En: Aportes (París), octubre de 1968. Véase también Wolf Grabendorff (ed.), Latin America and the Third World. Special Issue. Vierteljahresberichte. Probleme der Entwicklungsiänder. Forschungsinstitut der Friedrich-Ebert-Stiftung. Nr. 68, Juni, 1977 (Bonn).

${ }^{21}$ En relación con este proceso de aprendizaje, véase Mario Ojeda, Alcances y límites de la política exterior de México. El Colegio de México, 1976. 
zadas entre 1964 y 1970 por los democratacristianos de Chile y el estado petrolero de Venezuela esforzándose en llevar a cabo la primera organización de productores de materia prima, es decir la OPEP. Una segunda generación adaptó al ambiente latinoamericano las experiencias de la UNCTAD, del neutralismo e incluso del Gaullismo ${ }^{22}$, y aprendió a afrontar mayores riesgos.

Por una parte se comprendía perfectamente la propia posición en el seno del sistema americano (al cual no se oponía en principio, a diferencia de Cuba); por la otra se proponía, al igual que Francia dentro del subsistema europaoccidental, ampliar la propia capacidad de maniobra. Aleccionados de esta forma, ni Chile ni Venezuela cuestionaron los principios del sistema americano, sino más bien sondearon la posibilidad de asociarse con otros estados clientelistas y así fortalecer el propio poder negociador $^{23}$.

En el año de 1959 Venezuela, gobernado después de la caída de la dictadura de Pérez Jiménez por Acción Democrática, rechazó los avances cubanos a favor de una estrategia común de confrontación contra los Estados Unidos y en su lugar optó por colaborar con otros exportadores de petróleo. Esta decisión implicó una marcha larga y dispendiosa: la fundación de la OPEP en el año 1960, que entonces no suscitaba sino sonrisas entre los países industrializados pero que a mediano plazo resultó realista y exitosa tal como nos consta desde el otoño de 1973.

En cambio, los democratacristianos en Chile optaron por la colaboración en el interior de la América Latina. Vale destacar en ese contexto al mentor de una segunda generación de la política exterior latinoamericana, el Ministro de Relaciones Gabriel Valdés, a quien apoyaba conceptualmente Claudio Véliz, cuyo Instituto de Estudios Internacionales, fundado en 1967 en la Universidad de Chile y editor de la revista "Estudios Internacionales", atrajo colaboradores de gran talento de toda la América Latina.

Mientras evaluaban las experiencias del tercermundismo, del neutralismo, de las Comunidades Europeas y del Pacífico, pudieron desarrollar allí las primeras opciones de política exterior, colocando sus análisis a la altura de la discusión académica internacional.

\footnotetext{
${ }^{22}$ La Francia degaullista, obstinada en la "latinidad", se imaginaba el hemisferio austral como uno de los actores del sistema internacional, cuyas decisiones debían ampliar el campo de acción de París. Pero en lo esencial, todo se quedó en el gesto del viaje de De Gaulle a América Latina en 1964. Véase: Franz Schwarzbeck, Frankreich und Lateinamerika in der gaullistischen Ara. En: Vierteljahresberichte, Friedrich-Stiftung (Bonn). Nr. 66, 1976.

${ }^{23}$ Véase el artículo programático de Marcelo E. Aftalion, Poder negociador latinoamericano. En: Foro Internacional (México), Nr. 60, abril-junio, 1975.
} 
La Comisión Especial de Goordinación de América Latina, gBCLA brindó a la generación de Valdés la oportunidad de experimentar directamente en la práctica. La ogota había sido engendrada en 1964 como instrumento coordinador de los estados latinoamericanos que asistirían a la UNGTAD, dicho sea de paso, sin la participación de los Estados Unidos (un hito en la historia de las relaciones interamericanas). Sin embargo, fueron los colaboradores, de Valdés quíenes luego pusieron esta oficina al servicio de la política exterior: en mayo de 1969 , en forma de "Consen. so de Viña del Mar", un memorial coleetivo de agravios de los latinoame= ricanos frente a la recién posesionada administración de Nixon; en junio de 1970, como "Carta de Buenos Aires", dirigida a las Comunidades Europeas con miras a establecer una "rel ación especial" con Bruse= las. Mientras el "Gonsenso de Viña del Mar" no" surtió resultado alguno y sólo tomó forma dentro de la Organización de los Estados Amerí canos como foro de disçusión, la Gomisión Especial de Consulta y Negocia = ción (GEGON), la "Garta" sí tuvo cierto éxito.

En Bruselas, el año de 1971. se convirtió en el "Año Latinoameri= canono:25, con la institucionalización del llamado mecanismo de diálogo, con el viaje a Latinoamérica del entonces Ministro de Relaciones Exterìres de la Comunidad Europea, Ralf Dahrendorf; con la preparación de los acuerdos comerciales no preferenciales con algunos países del continente, así como con las tentativas de contacto con el joven Pacto Aridino, cuyo "nacionalismo económico" cré preocupación en el sistema americano. Muy activa en su disentimiento con Washington frente al "desafío americano", Bruselas mostró entonces su interés en impul= sar el diálogo latínoamericano a través de una relación especial con el Pac= to Andino, estructurado en forma paralela en lo que a integracionismo se refiere, reflejando así su herencia gaullista y su deseo de estableccer con= tactos horizontales dentro del bloque hegemónico estadounidense, para mermar a sí la rigidez del mismo.

En Bruselas, el entusiasmo por Latínoamérica decreció rápidamente después de 1973. Sin embargo, el continente avanzó otro buen trecho gracias a la pujanza que la generación de Valdés confirier a a su política exterior. El hecho de que entre 1968 y 1973 se hubiera logrado tanto, en el sentido de una desviación de la norma trazada por el sistema americano,

${ }^{24}$ Gabriel Valdés, 'América Latina y la política' del Nuevo Mundo: El papel de la $\mathrm{GQ}=$ misión Especial de Coordinación para América Latina gEoL.A, En: H.H. Godoy y D. Uribe Yargas, Politica Mundial siglo xxI, Bogotá, 1974. Acercá de $\mathrm{G}$. Valdés en el contexto chileno, véase: Manfred Wilhemy, Hacia un análisis de la política exterior chilena contem= poránea. Universidad Católica de Valparaíso, 1979.

${ }^{26}$ Gerhard Drekonja, "América Latina y las Comunidades Europeas: ¿Política Comercial o Politica Exterior? Nr. 16, mayo, 1974. 
sin duda algo tiene que ver con el compromiso militar de Washington en el Sureste Asiático, que distraía todas sus fuerzas disponibles, de modo que para América Latina no restara más que un "benign neglect".

Ahora bien, esto fue precisamente lo que la generación de Gabriel Valdés había aprendido: esperar el momento histórico más propicio para imponer decisiones que, aunque impliquen un riesgo, amplíen la propia libertad de acción ${ }^{26}$.

En 1972-73, los estados latinoamericanos alcanzaron su punto álgido en su apertura hacia la política internacional. Por una parte, la Carta de Derechos y Deberes Económicos de los Estados, propuesta por México ante la Conferencia de la UNCTAD en Santiago de Chile, alcanzó el cenit oratorio del tercermundismo latinoamericano: a pesar de toda su retórica, este documento también puso de manifiesto un fenómeno nuevo del "nacionalismo económico", a saber, la contención de la ya avanzada "transnacionalización" a favor de estados-naciones cooperantes. La Carta de Derechos y Deberes Económicos, al exigir para el estado (clientelista) el control exclusivo sobre la selección del modelo de desarrollo, las materias primas, el capital extranjero y el arbitraje en casos de nacionalización, hace hincapié -en contraposición a la tendencia existente en el Derecho Internacional- en la soberanía del estado-nación, creando con ello las bases para una contratendencia a la transnacionalización aparentemente incontenible ${ }^{27}$. Por otra parte, al hacer una perfecta fusión de la fórmula de la "tercera posición" del justicialismo de 1945 con el tercermundismo, la Argentina peronista-izquierdista de 1973 fortaleció el eje de los estados latinoamericanos que se encontraban en el límite de la tolerancia política del sistema americano.

Sin embargo, entre 1973 y 1975 , el clima político del continente dio un vuelco radical. Tecnocracias militares anticomunistas desalojaron a los partidarios del "nacionalismo económico" quienes habían buscado aliados procedentes del resto del Tercer Mundo. Volvieron a hacer su aparición los patrones de comportamiento "occidental", con lo cual América Latina se subordinó de nuevo al sistema americano.

Se abandonó el experimento de los representantes de la generación de

${ }^{26}$ El único que lo había logrado antes era el Presidente de México, Lázaro Cárdenas, quien esperó con la nacionalización del petróleo (1938) hasta que Gran Bretaña y los EE,UU. estaban 'demasiado ocupados con conflictos en Europa y el Japón como para intervenir directamente. Véase: Lorenzo Meyer, Mexico and the United States in the Oil Controversy, 1917-1942. The University of Texas, 1977.

${ }^{27} \mathrm{La}$ contracorriente a la tendencia hacia la internacionalización que existe en el Derecho Internacional, se manifiesta particularmente en la discusión latinoamericana del Derecho del Mar. Véase: F.V. García Amador, América Latina y el Derecho del Mar, Santiago de Chile, 1976. 
Valdés -ahora dispersados a los cuatro vientos - que consistía en negociar con el mundo exterior desde una (relativa) posición de fuerza. Obviamente, los Estados Unidos no pudieron aprovechar plenamente el vuelco político acaecido en el continente americano ya que, precisamente en ese momento, estalló la sorpresiva alza del petróleo, impuesta por una asociación de estados-naciones, sin que los consorcios transnacionales, que ya se tenían por invulnerables, pudieran, a la hora de la verdad, oponerles ninguna resistencia. Fue a raíz del éxito de una organización exportadora de materia prima que se derrumbó la homogeneidad del sistema internacional, cuyos centros de decisión se vieron obligados entonces a manejar simultáneamente una multitud de posibilidades a los más diversos niveles, con opciones de coalición que se multiplicaban entre sí.

Con esto se les llegó la hora, tanto analítica como táctica, a los creadores de la idea de la "interdependencia". 28 : en un sistema hegemónico, en el cual los estados clientelistas podrían reconquistar algunos elementos de poder a través de estrategias asociadas de conflicto, resulta conveniente para Washington pasar del control vertical a una participación, supuestamente cooperativa, con la consecuente distribución de pérdidas y ganancias.

De tal interdependencia se fue formando una de las columnas del trilaterismo ${ }^{29}$, que constituye el intento más reciente del sistema americano - aunque esta vez desde la defensiva - de adaptarse a constelaciones alteradas. Vistas con la perspectiva trilateral de Washington, a las tecnocracias militares, cuya doctrina de la seguridad nacional promete mantener el continente firmemente en las filas occidentales, no son objeto de ninguna prioridad. Washington sólo presta atención a problemas de tensión inmediata, para cuya solución le parece más adecuada la desactivación del conflicto en ciernes que la confrontación.

Como prueba patente del cașo está Panamá, quien pudo negociar exitosamente los tratados del Canal entre 1977 y 1979. Es así como esta América Latina, cuyo impulso en la política exterior se fue perdiendo después de 1973, se vio obligada de nuevo a acomodarse en la periferia del sistema americano; a renunciar en parte a su poder de négociación, que ya había incrementado notablemente. Sin embargo, este receso forzoso fue apro-

${ }^{28}$ Robert O. Keohane and Joseph Ney, Power and Interdependence: World Politics in Transition. Boston, 1977. También: David A. Baldwin, Power Analysis and World Politics: New Trends versus Old Tendencies. En: World-Politics (Princeton), January, 1979.

${ }_{29}$ Informaciones sobre la función de América Latina desde la perspectiva trilateral se encuentran en: Hugo Assman (ed.), Carter y la lógica del imperialismo. San José. Colección DEI-EDUCA, 1978. 2 tomos. 
vechado conceptualmente. Una tercera generación de política exterıor, heredera directa de Raúl Prebisch y Gabriel Valdés, aprovecha el tiempo, a partir de 1973, para dedicarse a una intensa labor intelectual. De las discusiones relacionadas con la UNGTAD, del diálogo Norte-Sur, de los esfuerzos hechos por lograr un eje Sur-Sur y, de los debates en torno al Nuevo Orden Económico Internacional, emanaron nuevos estímulos para continuar con el desarrollo del instrumento ya forjado. Uno de los centros de gravedad de la tercera generación de la política exterior fue establecida por Luciano Tomassini ${ }^{30}$, en un comienzo, a través del "Foro Latinoamericano", club de personajes latinoamericanos que se reunían periódicamente para analizar los sucesos de actualidad, ofreciendo apoyo para la toma de decisiones en materia de política exterior y política comercial externa. Y, luego, a partir de 1977, por medio del RIAL (Programa de Estudios Conjuntos sobre Relaciones Internacionales de América Latina), como agrupación de los más importantes centros de investigación de política exterior del continente, con el fin de que, a través de un intercambio de experiencias se formulara la teoría de la política exterior latinoamericana, que estaba en mora de definirse.

De ahí surgen numerosos nexos con el instrumento coordinador más eficaz de la emancipación latinoamericana, a saber, el SELA (Sistema Económico Latinoamericano) fundado en 1975, con sede en Caracas.

El SELA debe reconocerse como sucesor directo de CECLA, con la diferencia de que incluye a Cuba. En la Secretaría General del SELA, donde se busca en forma pragmática y realista un camino entre el Primer y el Tercer Mundo, se aspira a llevar paulatinamente a la práctica lo que parezca aprovechable en las discusiones teóricas: la elaboración de posiciones globales latinoamericanas para el Diálogo Norte-Sur; el perfeccionamiento de las tácticas para celebrar acuerdos de materias primas; la reanimación del diálogo con las Comunidades Europeas; la fundación de empresas latinoamericanas multinacionales de producción y comercialización como una defensa delantera contra las compañías transnacionales; la intensificación de la integración regional, el ensayo de la "autogestión" (collective self reliance) a favor de estilos auténticos de desarrollo que economicen recursos y energía. A través del SELA, América Latina alcanzó un alto grado de multilateralización en algunos de sus instrumentos de política exterior. Y, como consecuencia, no demoraron en aparecer observadores para concederle al "continente emergente" un valor más alto dentro del sistema internacional ${ }^{31}$.

\footnotetext{
${ }^{30}$ Los estuerzos hasta ahora realizados están resumidos en: E. Hill - L. Tomassini, América Latina y el Nuevo Orden Económico Internacional. Santiago de Chile, 1979.

${ }^{31}$ R.W. Fontaine, J.D. Theberge (eds.), Latin America's New Internationalis
} 


\section{En conclusiónin:}

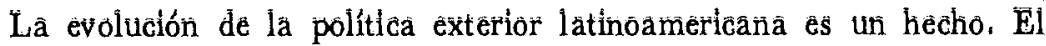
procesoso de aprendizaje de América Latitia dentro dēl sístemà internaciónal empieza a arrojar resultadōs, tânto conceptuales comó práctícos.

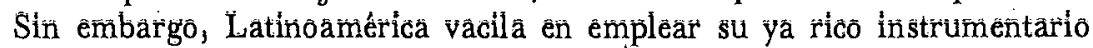

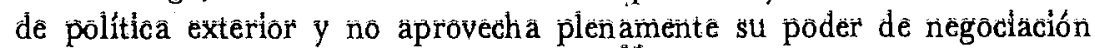

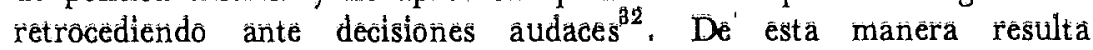
contradictoria la observación de que el ideario de una política exterior

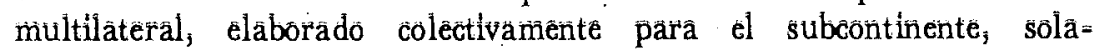

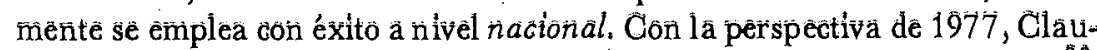

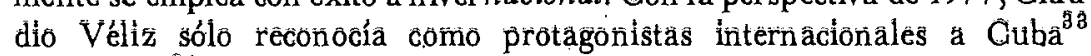
y al Brasili ${ }^{34}$. A comienzoos de la década de lôs ochentâa ya hay que vôlvêr

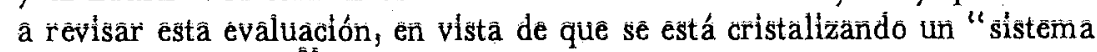

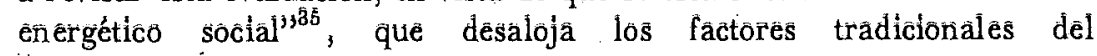

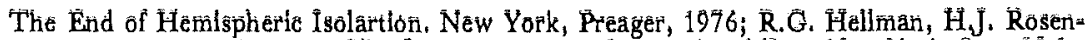
baum (eds.), Latin Amerlai: The Seareh for a Nezu Intemational Role. New York. Sage-Hâlsted, 1975, A.F. Lowenthâl; A. Fishlow, Latin Amêrica's Emergence, Toward a U.S. Ress= ponsese. New York Forelgn Pollicy Association, 1979; Edward S. Milenky, Latin Americás

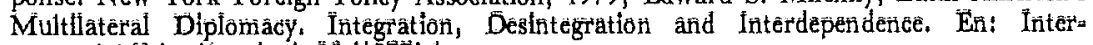
nátional Affảrs (Lóndoñ), 53 (1977) 1 .

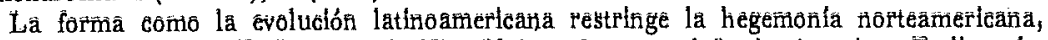
la muestra Abraham $\vec{F}$, Lowenthal. The United States and Latin Annêricica: Ending the Hegemonle Presumption. En: Foreign Affalis (New York), 55, (1976) 1.

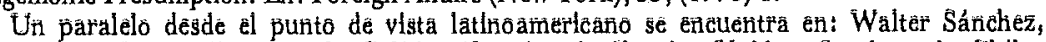
Idealismo e Imperlallsmo en la Pólítica Extertor de Ėstados Unidos. Santiago de Chile:

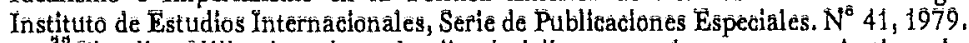

"Giaudio Véllz Introduce là "audadia" como elementito constitutivô de uñâ pô"

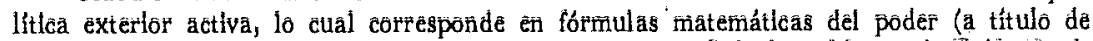

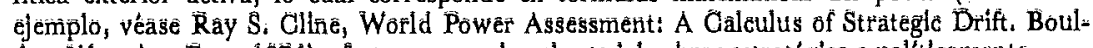
dêri: Westview Pressis 1976) ã fâctorès como la voluntâd de obrar estratégica o polítlcánentente.

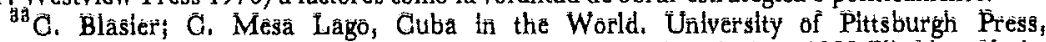
1979; Jâcques Levescoue, The Sovlet Untonin añd the Guban Revolutiont 1959=77. New York:

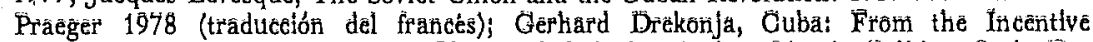

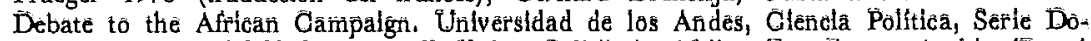

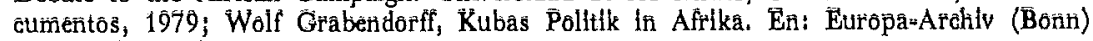
XXXYV (1979), $1 \hat{3}$,

${ }^{a}$ El resumen más actualizado de la polítca exterior brasilera: Wayne E. Selcher

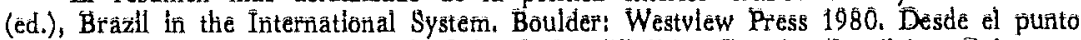

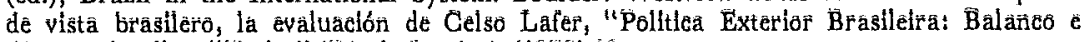
Perspectivas" en "Dados" (Río de Janéiro), (1979) Z2.

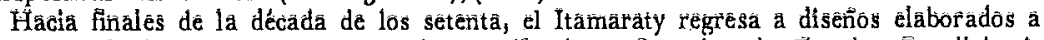

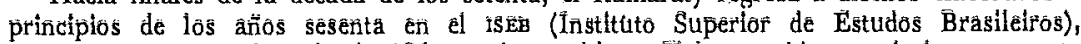

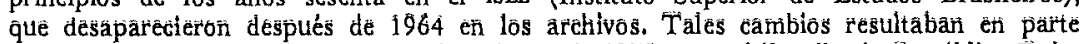
debido al notoriamente famosó acuerdo atómico de 1975 entre el Brásil y la Répúblićá Fédes

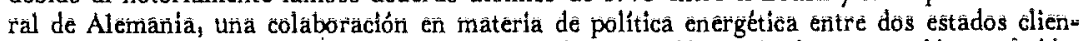

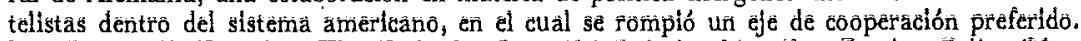

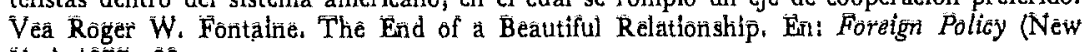
Yor) $1977=28$.

${ }^{3 b}$ Véâse Sanmuel Z. Glatustorer, The Energy Social System. En: The Anals of the 
poder para dar cabida a los recursos energéticos controlados por estadosnaciones. Mientras el Brasil retrocedía por su vulnerabilidad en materia de hidrocarburos, Venezuela ${ }^{36}$ como potencia cada vez más importante del Caribe; México como estado-nación estable que, frente a los Estados Unidos, hace uso de sus enormes recursos petrolíferos para enmarcar en ellos la definición de un paquete de problemas bilaterales, que de repente ya no pueden obviar los Estados Unidos inundados por las migraciones latinoamericanas.

El poder de negociación mexicano se basa, no en el último lugar, en estudios profundos realizados por analistas de política exterior provenientes del Colegio de México, donde se ha aprendido, en una labor preparatoria de 20 años, a reaccionar en forma brillante frente a desafios de esta índole $^{37}$.

Por otra parte, el éxito obtenido por algunos estados latinoamericanos repercute sobre el conjunto incluyendo a los "occidentalistas" como Argentina o Chile. Pero aún así, la suma de tales tendencias no constituye todavía material suficiente para una teoría de la política exterior latinoamericana. Esta será una tarea que deberá cumplirse durante los años ochenta, si el continente quiere consolidar su (relativa) capacidad de maniobra, lograda en las pasadas dos décadas. Como consecuencia de las circunstancias geopolíticas, América Latina no está buscando en este contexto apoyarse en el concepto de los estados pequeños y medianos (lo que podría servir de puente hacia el Canadá) ${ }^{38}$ sino que tiende a aceptar un papel de clase media ${ }^{39}$ en el sistema internacional, con una variedad de posibilidades para constituir alianzas, según si lo que va a predominar son los conflictos o los comportamientos cooperativos entre la "élite", o sea, los países industrializados, y el "proletariado": los estados africanos y asiáticos.

American Academy of Political and Social Science (Philadelphia), July, 1979. Según Clausner, el sistema internacional está sufriendo una metamorfosis, porque en el campo de la energía, la red tradicional de empresas transnacionales está siendo reemplazada en medida creciente por estados-naciones que cooperan entre sí. Las conclusiones para Venezuela las saca: Alberto Quirós Corradi, Energy and the Exercise of Power. En: Foreign Affairs (New York), Summer, 1979.

${ }^{36}$ Robert D. Bond (ed.). Contemporary Venezuela and its Role in International Affairs. New York University Press 1978. También: Demetrio Boersnes, Venezuela y el Caribe: Presencia cambiante. Caracas. Monte Avila, 1978.

${ }^{37}$ Por ejemplo el número especial de Foro Internacional, XIx (1978) 2, sobre "México y Estados Unidos" ¿Un nuevo tipo de relaciones? Véase también los excelentes trabajos en el Centro de Investigaciones y Docencia Económicas (CIDE) de México.

${ }^{3}$ R. Barry Farrell, América Latina y Canadá frente a la política exterior de los Estados Unidos. México: Fondo de Cultura Económica, 1975.

${ }^{39}$ Francisco Orrego (ed.), América Latina: ¿Clase media de las naciones? Santiago de Chile: Instituto de Estudios Internacionales, 1979. 
Aldo Ferrer ${ }^{40}$ tiene razón en afirmar que la dependencia latinoamericana debería abrirse en todo caso en dirección a una "teoría de la independencia". Si esto se lograra, aunque sea en parte, los pesimistas de oficio tendrían que abandonar por fin su "plus c'est la même chose"41.

Sin embargo, los latinoamericanos capaces de desarrollar una acción en la política exterior - para muestra, el compromiso de Cuba en el Africa- expondrían el equilibrio, de por sí visiblemente trastornado, del orden mundial establecido en 1945. Esto es algo que de ninguna manera teme afrontar el continente latinoamericano, donde la estabilidad del bloque hegemónico americano posterior a la Segunda Guerra Mundial se considera más bien como una carga que como una virtud.

${ }^{40}$ Aldo Ferrer, Notas para una teoría de la independencia. En: Comercio Exterior (México), $\operatorname{xxxx}(1979) 8$.

${ }^{41}$ David Félix, Latin American Power: ¿takeoff or plus c'est la même chose? En: Studies in Comperative International Development, xur (1977) 1. Aún más pesimista: Richard L. Clinton, América Latina, la región que nunca se desarrollará. En: Comercio Exterior, XxvirI (1978) 7. Según escenarios tan deterministas simplemente no hay futuro para América Latina. Por supuesto que no consideran allí los saltos de calidad, tal como resultaron posibles contra toda lógica ortodoxa de la política exterior, después del nacimiento de la OPEP, por cuyo padre se reconoce al venezolano Pérez Alfonzo $(+1979)$. A este respecto véanse las reflexiones de Juan Carlos Puig, Justicia y Realidad Social Internacionales. Reflexiones teóricas y repercusiones sobre la autonomía latinoamericana. En: Mundo Nuevo (Caracas), I (1978) 2. 